\title{
CIÊNCIA E PSEUDOCIÊNCIA NA ADMINISTRAÇÃO
}

\section{Eduardo Picanço Cruz, D.Sc.}

Fabio do Nascimento Siqueira da Silva, M.Sc.

\section{RESUMO}

O presente artigo faz referência a um termo contemporâneo denominado PSEUDOCIÊNCIA. 0 mesmo sugere a possibilidade, bem como o fato da falseabilidade da ciência por parte de alguns que de maneira lúcida e pensada o fazem intentando várias questões como: aceitação, sucesso, promoção pessoal, ludibriação, e por que não, engano de outros e de si mesmos. São apresentados alguns exemplos genéricos, por questões éticas, que devem servir de chamada para discussões futuras sobre a profissão do administrador. Não se pretende chegar, ainda nesse artigo, a conclusões definitivas, exatamente para não criar outras pseudoverdades além das apresentadas no texto.

Palavras-Chave: Ciência. Pseudociência. Administração. Gurus da administração.

\begin{abstract}
This article refers to a contemporary term called PSEUDOCIÊNCIA. This also suggests the possibility, as well as the fact of the science could be false by some that so lucid and thought they do bring several issues such as: acceptance, success, personal promotion, and why not, deception of others and themselves. Some generic examples are presented, for ethical reasons, which should serve as a call to future discussions on the profession of the administrator. It is not intended to reach, yet this article, the final conclusions, not just to create pseudo-truths other than those presented in the text.
\end{abstract}

Keywords: Science. Pseudoscience. Administration. Gurus of the administration. 


\section{INTRODUÇÃO}

Quando pensamos em ciência, somos postos pensar em conhecimento, pois acreditamos que não se faz ciência sem conhecimento. Ressaltamos que ao falarmos de conhecimento o abordamos em toda sua esfera, seja ele empírico, o qual entendemos ser a base dos outros tipos de conhecimento, filosófico, teológico ou científico que é onde queremos nos ater.

Ao falarmos de conhecimento, quase que automaticamente somos levados a refletir acerca da evolução por que passa o mundo. Pessoas, conceitos, religiões, tecnologias, organizações, relações interpessoais são elementos que fazem parte deste cenário evolutivo e mutante. A necessidade do entendimento e da adaptação a essas mudanças faz com que os indivíduos se empenhem, cada vez mais em busca do conhecimento (SLIPÓI, 2001). Isso pode ser um terreno fértil à propagação da pseudociência.

O homem, desde os primórdios, por ser diferente dos outros animais, vem tentando se superar, mudando a realidade onde vive, transformado e adaptando os elementos que os cercam em busca de um conforto, mesmo que seja passageiro. Dessa 2 natureza inconstante e mutante, surge a motivação para o desenvolvimento intelectual que faz com que apareçam idéias novas a cada momento. Como exemplo dessas ideias no mundo corporativo pode-se citar: mecanismos de transporte e armazenagem de produtos, eletricidade, informática, redes de computadores interligados, internet, tecnologia via satélite. Essas mudanças tendem a transformar as condições de vida dos seres humanos.

Reportando-nos ao passado, mais propriamente dito a Revolução Industrial, percebemos que muitos trabalhadores do campo deixaram seus postos de trabalho rural e foram trabalhar nas cidades, nas indústrias que surgiam, causando uma grande transformação socioeconômica principalmente na Inglaterra e posteriormente por todo mundo. Ao contrário da situação narrada, hoje notamos um outro tipo de revolução, não a industrial como a do passado, mas de ordem intelectual, uma revolução, onde é exigido do trabalhador o desprendimento da sua força muscular - outrora tão importante na indústria - em detrimento à valorização de aspectos como a criatividade, inteligência, capacidade de raciocínio lógico e outros. Esta revolução vem crescendo de maneira gradativa nas organizações, mostrando a sua força e modificando o conceito de trabalho.

Percebe-se também a distância que existe entre a oferta de trabalho e a qualificação profissional para preencher a oportunidade oferecida. Essa distância pode ser atribuída, entre tantos outros fatores, a desqualificação profissional. Este tem sido pode ser um dos elementos que aumentam a estatística do desemprego, sem generalizar.

Um indicador da crescente percepção da importância do conhecimento, pode ser observada em empresas que se aplicam em conhecer o nível do "conhecimento" dos seus funcionários, bem como, incentivando-nos na aquisição, cada vez maior desse novo tipo de "matéria-prima" como fator vital para o seu desenvolvimento. Normalmente os temas desses eventos versam sobre "talento humano", inteligência competitiva, engenharia do conhecimento. Em comum, encontramos a reafirmação da importância de uma ação sistemática facilitadora, por parte da organização, no sentido de criar, medir, utilizar e reter o conhecimento. 
Sendo assim, o que fica claro é que as organizações que têm adaptarem a essas "novas" exigências do mercado, no sentido da incorporação do conhecimento em seu processo de gestão organizacional, vêm aumentando a sua capacidade competitiva e promovendo a qualificação de seu quadro de pessoal, donde os trabalhadores, passaram a ter conhecimento sobre as suas funções individuais, contribuindo assim para o atingimento dos objetivos organizacionais.

Enfim, o que queremos enfatizar é que essa primeira abordagem versa sobre o conhecimento em forma de ciência, e é aí que consiste o que entendemos por ponto nevrálgico da nossa argumentação, pois se temos encontrado no mercado empresas e pessoas ávidas por conhecerem, percebemos que há oferta e "boa" oferta de ciência, mesmo que a toque de caixa, ciência sem esforço, ciência sem método, ciência sem sistematização, ciência sem ciência e é sobre esse novo elemento, como já dissemos no início de nossa discussão, chamado de pseudociência que a partir de agora passamos a discutir.

\section{A CIÊNCIA}

As primeiras evidências do que atualmente é considerado "ciência" são encontradas entre os gregos do período clássico: um conhecimento verdadeiro, universal, necessário e, acima de tudo, fundamentado. A filosofia grega, surgida nos séculos VII e VI a.C., diferenciava-se em tudo das concepções de pensadores orientais a exemplo de Confúcio e Lao-Tse. Estes vinculavam suas teorias à religião a princípios 3 morais. Por outro lado, as formulações dos pré-socráticos e dos que os seguiram caracterizavam-se pelas posturas racionalista e desencantada de um saber único, "que se procurava pelo mero desejo de saber e não pela sua utilidade prática" (FONSECA, 1997). Portanto, a filosofia era a ciência ou a ciência era a filosofia. Estavam umbilicalmente ligadas e nessa junção separavam o pensamento mítico e religioso de outro, de ordem reflexiva, baseado na observação e na interação homemnatureza.

Segundo Aranha \& Martins (1993) o filósofo era o sábio que refletia sobre todos os setores da indagação humana. Não para menos, pensadores como Tales, Pitágoras e Aristóteles não só ostentavam características dos modernos filósofos mas também se exprimiam por um conhecimento de ordem mais prática e utilitária. Eram geômetras e matemáticos os dois primeiros, e físico e astrônomo o terceiro.

Sócrates fornece exemplos valiosos da interação inicial entre ciência e filosofia. Passava a maior parte de seu tempo em praça pública valorizando o mundo da experiência vivida. Relacionava-se com as pessoas nos seus mais "diversos saberes" e atividades, submetendo tudo à reflexão ou fazendo uso, avant la lettre ${ }^{1}$, do princípio cartesiano da dúvida metódica. Formulava conceitos que procuravam captar a essência geral e real das coisas, atividade na qual procurava romper com emoções, tradições, princípios de autoridade e critérios de conveniência culturais e políticos. Em vez de partir de uma certeza determinada por princípios apriorísticos, operava os mecanismos valorizadores da experiência, afirmando o princípio de que nada sabia.

\footnotetext{
1 "antes que a expressão tivesse sido inventada".
} 
No entanto, segundo Aranha \& Martins (1993), é a partir da revolução metódica iniciada por Galileu no século XVII que se inicia, de fato, a cisão entre filosofia e ciência, com esta firmandose como categoria autônoma.

Na medida em que o Ocidente, forjado pelas revoluções industrial e científica, passa a se interessar cada vez mais no "como as coisas acontecem" em detrimento do questionamento muitas vezes metafísico dos "porquês", a ciência avança em sua cisão com a filosofia. 0 renascimento, o humanismo, o naturalismo, os descobrimentos e o experimentalismo preparam essa nova orientação. Descartes tem como ponto de partida a "busca de uma verdade primeira que não possa ser posta em dúvida” (ARANHA \& MARTINS, 1993). Desta maneira converte a dúvida em método, com regras que, devidamente observadas, conduziriam ao conhecimento verdadeiro. Assim ele apresenta quatro regras fundamentais para tal conversão:

- regra da evidência: nunca aceitar alguma coisa como sendo verdadeira se isto não for evidente, ou seja, caso essa não se apresente clara e distintamente ao pesquisador sem deixar margem de dúvida, não pode ser considerada como verdadeira, assim, caso a proposição não atenda à condição de verdade evidente, deve ser imediatamente excluída;

- regra da análise: seria observar que a análise da questão procura separar o problema em um maior número possível de partes detalhadas para entender as particularidades de cada uma e sua função como componente do todo;

- regra da síntese: os pensamentos devem ser conduzidos ordenadamente, começando pelos objetos simples e fáceis de se conhecer e entender e, aos poucos, ir somando às partes para poder elevar o grau de complexidade das questões, esse processo exigiria uma ordenação análoga à geometria, prescrevendo a possível ordenação de todo saber nesta forma, a dedução;

- regra da enumeração: procurar sempre enumerações tão completas e revisões tão gerais que o pesquisador fique certo de não omitir nenhuma; a enumeração controla a análise, da mesma maneira que a revisão controla a síntese.

Desse modo, partindo da intuição, desencadear-se-ia um processo dedutivo para comprovar e explicar determinada tese, o método experimental apresenta a seguinte seqüência:

- observação: "ação rigorosa, precisa e metódica, orientada para a explicação dos fatos" (ARANHA \& MARTINS, 1993, p. ?). Essa etapa necessita tanto de perspicácia do pesquisador quanto do apoio oferecido por instrumentos como microscópios, telescópios, balanças etc;

- hipótese: é a explicação provisória dos fenômenos observados. Tem o papel de gerar uma organização dos fatos para explicá-los inicialmente. Essa hipótese pode ser formulada por indução, dedução ou analogia;

- experimentação: para que uma hipótese seja considerada científica, deve ser passível de verificação. Assim, faz-se necessário o teste da explicação que o pesquisador apresenta para o problema. Trata-se de uma análise das variações do fenômeno em situações alternativas, programadas. Desse modo, quando a experimentação não 
confirma a hipótese o trabalho deve ser reiniciado;

- generalização: é a busca de relações constantes entre as condições do experimento e outras possibilidades. As generalizações podem ser divididas em empíricas (leis particulares) ou teóricas (nomotéticas ou gerais, leis propriamente ditas).

Assim pode-se recorrer a Ruiz (1979) para apresentar o conceito de ciência que seria o "conjunto de conhecimentos organizados relativos a uma determinada matéria, comprovados empiricamente". Já a pseudociência para Carl Sagan², são teorias que parecem ter tido um tratamento científico mas se baseiam em informações insuficientes ou ignoram pistas que apontam para outro caminho.

Seguem algumas definições para filosofia e ciência:

- "filosofia é o estudo que se caracteriza pela intenção de ampliar incessantemente a compreensão da realidade, no sentido de apreendê-la na sua totalidade" (FERREIRA, 1988);

- 'as ciências se especializaram e observam 'recortes' do real, enquanto que a filosofia jamais renuncia a considerar o seu objeto do ponto de vista da totalidade" (ARANHA E MARTINS, 1993);

- "a ciência é o conhecimento das consequências e dependências de um fato com respeito a outro; a base disso, partindo do que podemos fazer no presente, saberemos realizar outra coisa se queremos fazer agora ou outra semelhante em qualquer ocasião" (HOBBES, 2000);

- "ciência é o conjunto organizado dos conhecimentos relativos ao universo, envolvendo seus fenômenos naturais, ambientais e comportamentais" (LONGO, 1996).

Este último autor divide a ciência em pura ou fundamental, quando desvinculada de objetivos práticos, e aplicada quando visa conseqüências específicas. Além disso, através de seu conceito, pode-se entender o papel das Universidades no desenvolvimento da ciência, pois o que está fundamentado, acima de tudo, nesse conceito, é a necessidade do homem ter acesso ao conhecimento, logo, a ética que envolve a ciência é a da divulgação. Faz necessário, assim, que as defesas de teses, dissertações ou trabalhos de pesquisa sejam sempre realizados em audiência pública, acessível a qualquer interessado. Congressos, simpósios e conferências servem como difusores desse conhecimento gerado nas mais diversas localidades.

Outro instituto importante para a divulgação da ciência é premiação. Isto percebeu o químico e engenheiro sueco Alfred Bernhard Nobel, que direcionou sua fortuna para, anualmente, premiar os cientistas das mais diversas áreas que se destacaram com suas pesquisa. Todos esses instrumentos permitem ao homem engrandecer o objetivo da ciência que é a descoberta e elucidação dos fenômenos. Não há invenção na ciência. Segundo Longo (1996), o trabalho do cientista é um processo social, já que as teorias e conclusões devem sobreviver a um período de debate, avaliação crítica e, acima de tudo, à repetição dos ensaios e testes, para que esses novos conhecimentos sejam incorporados à ciência universal, conseqüentemente esse conhecimento deve ser considerado bem público e acervo da humanidade.

\footnotetext{
2 Ex-professor de astronomia e ciências espaciais da Cornell University e pesquisador da NASA.
} 


\section{A PSEUDOCIÊNCIA}

Segundo Sagan (2003) pseudociência por definição é a falsa ciência. Na vida prática pseudociência é toda atividade em que se tente afirmar e/ou comprovar algo sem ser utilizado e respeitado o método científico.

No mundo existiram e existem muitos profetas, videntes, curandeiros, falsos cientistas, falsos médicos e até, hoje em dia, falsos administradores. Essas pessoas afirmam muitas "verdades" baseadas em diversas teorias que elas constroem, através de métodos obscuros e controversos. São teorias que não se sustentam se forem submetidas a um exame científico idóneo, apresentando falhas e erros de método e procedimento, além disso e seus resultados não refletem uma base ou sustentação teórica nem experimental que as legitimem cientificamente.

A pseudociência é vista e divulgada ao longo da história da humanidade, por ser extremamente atraente. Ela é de fácil construção para quem a deseja criar, pois não respeita as normas, métodos, etapas e procedimentos que uma teoria cientifica de verdade teria que obedecer e seguir passo a passo. No contexto de quem a observa ela costuma apresentar os resultados que o observador deseja ver e é de fácil entendimento. Isto, obviamente, é algo muito sedutor para as pessoas, mais notadamente para as menos educadas, esclarecidas e críticas, que, por conseguinte, são mais fáceis de serem enganadas e ludibriadas por esses pseudo-cientistas e charlatães. Por exemplo: seria muito fascinante se houvessem extraterrestres escondidos no Triângulo das Bermudas sequestrando navios ou mortos, usando mãos humanas para transmitir mensagens a parentes, e existem as mais diversas pessoas buscando argumentos para provar serem esses fatos verdades, porém, essa busca não se dá através da metodologia científica tradicional.

A pseudociência é uma arma muito perigosa quando na posse de pessoas inescrupulosas e mal intencionadas, haja vista, que podem com suas falsas teorias, construírem previsões e afirmações, doutrinas e dogmas, travestidos de ciência, atingir seus objetivos pessoais podendo ser nocivos e perigosos à sociedade. Essas pessoas possuem a capacidade de ludibriar, persuadir, lesar, convencer outros cidadãos a agirem de acordo com seus nefastos interesses para beneficio único e exclusivo delas próprias (SAGAN, 2003).

Em somatório, esses falsários, na maioria das vezes, costumam ser pessoas de excelente oratória, ótima postura, belas vestimentas e postura séria e firme. Isso tudo, nada mais é do que mais uma artimanha dessas pessoas desonestas para conseguir credibilidade para suas afirmações, e consequentemente, apoio para suas causas. Além disso, o público alvo desses pseudo-cientistas são pessoas mais humildes e sem grandes conhecimentos. Logo, esses "truques" usados costumam convencer uma grande quantidade de pessoas.

0 mais grave no caso dos pseudocientistas ocorre quando se trata de um político importante ou religioso poderoso. Eis que, nesses casos, ele tem o poder de conquistar milhares de mentes para fins terríveis como, dominar povos, criar guerras sem sentido para beneficio próprio e de sues aliados, criar reinos e impérios declarados ou não para usurpar o dinheiro, bens e terras da população, frisando apenas alguns exemplos.

A pseudociência também pode aparecer quando um cientista sério, por algum motivo, é levado a cometer erros, desvios, ou se equivocar em algum procedimento ou processo dentro do seu trabalho científico. Invariavelmente, isto o levará a no final da sua pesquisa científica 
não produzir ciência, mas sim, pseudociência.

Essa espécie de pseudociência difere da anterior no aspecto em que esta é involuntária e a outra é voluntária e é construída de má fé. Logo, este segundo tipo é bem mais difícil de ser evitada, pois o erro ocorre sem a percepção do cientista. Isto a torna complicada até de desmascará-la, porque esse engano que a levou fugir da verdade pode ser tão sutil a ponto de ficar invisível dos olhos inclusive de outros cientistas que venham, porventura, a se deparar com este trabalho científico.

\section{DISTINÇÃO ENTRE CIÊNCIA E PSEUDOCIÊNCIA}

A ciência se confunde com a pseudociência na fronteira entre o conhecimento e a ignorância. Enquanto a ciência, ao mesmo tempo em que gera o conhecimento é também baseada nele, a pseudociência é baseada na ignorância, que por sua vez, é fruto da limitação do conhecimento. Em virtude disso gera mentiras, enganos, erros, contradições, visões distorcidas da realidade e leva a manipulações de pessoas e a malefícios para a população de como um todo.

Distinguir a verdadeira ciência da falsa ciência, muitas vezes é tarefa complicada. A pseudociência, de modo geral, está perfeitamente disfarçada com a fantasia de seriedade e de ciência séria e real. Isso acontece por dois motivos distintos: 1) o fato dela poder ser feita por charlatães mal intencionados, que usarão de todos os artifícios e técnicas possíveis e imagináveis para mostrar suas conclusões pseudocientíficas mentirosas passarem por verdadeiras. Para tal feito são dotados de um arsenal de técnicas. Para passar uma imagem de autenticidade e seriedade vestem-se da maneira mais impecável e formal possível, ostentam bens como carros, relógios, joias de alto valor financeiro, usam técnicas de oratória mirabolantes, ficam sempre sérios e sisudos, entre outros métodos.

Esse truque tem enormes chances de funcionar com pessoas ignorantes no assunto específico de que os falsos estudiosos estão tratando ou com pessoas que não estejam extremamente entendidas e embasadas sobre os temas por eles abordados. Pois, além deles serem muito hábeis no convencimento costumam dizer o que se anseia ouvir. Isso é muito perigoso, pois somos tentados a acreditar no que desejamos ser realidade e temos dificuldade em acreditar em algo que nos contrarie ou aceitar o fato de algum evento ou problema não tem explicação conhecida até o presente momento. 2) é o fato da pesquisa, em sendo realizada por cientista bem intencionado, não estar imune de sofrer algum erro ou imperfeição no seu processo, transformando-a de ciência em pseudociência. Tal evento pode ser muito difícil de ser detectado, uma vez que um pequenino erro, quase imperceptível pode comprometer toda a autenticidade dos resultados da pesquisa.

O cientista é passível de cometer esta falha por diversos determinantes diferentes, como: o apego emocional com a pesquisa. Isso poderia fazer com que as emoções e desejos próprios influenciassem o estudo, ou plausível é a atitude do cientista não cumprir exatamente da forma correta algum procedimento do método científico, ainda, a possibilidade de alguma hipótese não ter sido testada satisfatoriamente para que se pudesse desvendar o seu erro, a amostra com que foi feito o teste da hipótese, pode não ter sido satisfatória ou distribuída de maneira inadequada para validá-la cientificamente, porém, há a hipótese do cientista não ter observado todas as variáveis que envolvem a sua teoria, tendo esquecido de alguma delas, o que poderia mudar drasticamente as conclusões e os resultados da pesquisa (SAGAN, 2003).

Portanto, o limiar que distingue a ciência da pseudociência é uma linha das mais sutis e ténues. Assim sendo, quando se almeja realizar ciência é obrigatório se ter o máximo 
seriedade, cautela, profissionalismo, pensamento o mais critico possível e questionador, pois agindo assim, dificilmente haverá conflito entre os conceitos de ciência e pseudociência.

\section{A CIÊNCIA NA ADMINISTRAÇÃo}

Ao falarmos sobre ciência na administração, na verdade temos que falar na administração como ciência. Atualmente quando pensamos em administração e nos "modelos" administrativos apresentados no mercado, são nítidas duas percepções: 1) empresas vanguardistas e contemporâneas apegadas a processos científicos estudados, desenvolvidos e disseminados por estudiosos como Taylor, Fayol, Ford, Gulick e outros - quando fazemos tal afirmação pensa os em questões como administração científica, seleção científica do trabalhador, estudo de tempos e movimentos, desenvolvimento da linha de produção em massa, disseminação do planejamento, organização, direção, coordenação e controle, funções administrativas e outros tantos fatores que de forma científica contribuíram para que a administração, ou melhor, a gestão administrativa chegasse ao patamar exitório atrual.

Sob outro prisma, o qual apontaremos como ponto 2) é nítido o surgimento de gestores "gurus" da administração que pensam levar organizações ao topo da pirâmide por meio de procedimentos nada científicos e extremamente questionáveis, são viagens a países orientais em busca do encontro do "eu", escaladas a montes e montanhas, caminhadas por sobre brasas, são gestores que viram monges e monges que viram gestores... cabe aqui uma pequena ressalva ao termo "guru", que segundo o Dicionário Global da Língua Portuguesa significa: "chefe espiritual de uma aldeia, guia espiritual". A função se aplicaria bem a uma aldeia espiritualista, mas não numa empresa, ou será que estamos transformando a organização em local de disseminação de conceitos espirituais ao invés de aplicação de modelos científicos que promovam longevidade por meio de vantagem competitiva?

Encontramos ainda hoje empresas que não abdicam da essência administrativa em seus processos e nem por isso deixaram de ser vanguardistas, muito pelo contrário, talvez a visão e utilização dos processos administrativos científicos seja o elemento principal no sentido de fazer com que as mesmas alcancem liderança em seus respectivos segmentos. Falamos aqui de empresas como FIAT, General Eletric, 3M, para citarmos alguns exemplos, não nos desfazendo de outras tantas atuantes no mercado.

Pois bem, é fato patente que a ciência, para muitas organizações, há muito já deixou de ser fator sinequanon para tomada de decisões, bem como fator orientador das ações organizacionais, talvez pela evolução, talvez pelo resgate do "sagrado" em detrimento do perecível, não sabemos e nem queremos aqui discutir tais questões, mas cabe a nós administradores e gestores repensarmos sobre as mesmas.

\section{A PSEUDOCIENCIA NA ADMINISTRAÇÃO}

A Administração, por ser uma ciência muito recente, ainda carece de estudos mais profundos sobre os assuntos inerentes a essa ciência. Percebemos a aparição estudos muito superficiais e ausentes de embasamento teórico suficiente para comprovar as teorias propostas, por esse aspecto a Administração é um campo fértil para pseudocientistas atuarem livremente. Isto tem se comprovado na prática com muitos ditos administradores, consultores, ou autores de livros sobre a ciência da Administração que na realidade não tem embasamento teórico ou experimentação suficiente que sustentem cientificamente suas teorias. 
Os pensadores da pseudociência muitas vezes interessadas apenas em auferir lucro financeiro, fama e notoriedade de forma fácil e rápida não levam o estudo da ciência da Administração a sério, o que os transforma em pseudo-administadores ou em pseudoscientitas de Administração. Isso é muito grave, pois, tais sujeitos desmoralizam profissionais sérios que praticam a ciência administrativa de forma escorreita, respeitando as normas e os procedimentos científicos.

Pois bem, diante do exposto, o desafio a ser vencido pelos militantes da correta e séria Administração, tanto no âmbito da ciência quanto na esfera prática é saber diferenciar o charlatão do real cientista. Do cenário de hoje em dia, pode-se constatar o alto grau de mistura e confusão existente entre os estudos, teorias, pesquisadores, livros, professores, palestrantes honestos embasados na ciência dos inescrupulosos amparados com em suas pseudociências.

Esse fenômeno ocorre em todos os níveis da Administração. Há desde grandes empresas acreditando nas ideias de charlatães da área - por esse motivo são levadas a gastar volumosas quantias de dinheiro em consultorias ou em implementação de modelos de gestão criados por essas pessoas - até, da mesma maneira, há pequenas empresas, professores e estudantes acreditando e reproduzindo essas teorias sem embasamento científico, aleatoriamente, não se preocupando em usar o senso crítico para analisá-las e testá-las de forma a comprovar se realmente são verdadeiras ou não.

Portanto, só com pessoas engajadas no propósito de livrar a Administração desse obscurantismo e atraso criado pelos pseudo-administradores e suas teorias, é que entendemos que recriar um modelo de Administração é vital não só para as organizações e classe dos administradores, pois somente com a colaboração de administradores sérios e capazes poderemos almejar alcançar o progresso. Resaltamos que quando falamos em "recriar um modelo", na verdade não falamos em "reinventar a roda", mas sim em fazê-la rodar de maneira suave, mesmo que por estradas esburacadas.

\section{CONCLUSÃO}

A administração e suas áreas afins nasceram das importantes pesquisas realizadas por estudiosos de outras ciências. Dessa forma, fica tão difícil caracterizar um campo único para o administrador atuar e garantir como "seu".

Esse fato tente a favorecer o surgimento desses pseudocientistas que se aproveitam dessa fragilidade para se infiltrar como consultores, autores e conselheiros que atuam muito mais como "magos" e "gurus" do que como assessores, propriamente dito.

0 estudo da administração é árduo e demorado. Entender o funcionamento de uma empresa demanda conhecimentos, no mínimo intermediários, de matemática, estatística, direito, filosofia, antropologia, sociologia, psicologia, economia e engenharia, por exemplo. Todas essas ciências, que ajudaram a formar o pensamento da administração, servem agora como apoio básico para os inúmeros desafios que esse profissional deve estar pronto para encarar no dia-a-dia empresarial.

As escolas de administração do Brasil ainda estão longe, em sua grande maioria, de formar esse profissional e de exigir em sala de aula uma postura apropriada. Esses formandos têm que estar muito bem preparados para enfrentar um mercado que ainda não os reconhecem, $\mathrm{e}$ que prefere, muitas vezes, o suporte dos "magos e gurus", ou simplesmente ou profissional dessas ciências de apoio. 
Não se pretende fazer desse artigo uma apologia anti-"estrangeiros" na administração, mas apenas lembrar que estes não têm, em sua formação, a finalidade de se enfrentar o dia-a-dia das empresas. Os departamentos de administração das Universidades brasileiras devem aceitar mais a colaboração dos administradores para fortalecer o pensamento dessa ciência, e nesse sentido, incluir professores com essa formação específica. Não se trata de desdém para com suas raízes, mas que busca ocupar seus espaços.

\section{BIBLIOGRAFIA}

ARANHA, M.L. de A; MARTINS, M.H.P. Filosofando: introdução à filosofia. 2. ed. São Paulo: Moderna, 1993.

BRASIL. Medida Provisória n. 2200-2, de 24 de agosto de 2001. Institui a Infra- Estrutura de Chaves Públicas Brasileira - ICP-Brasil, transforma o Instituto Nacional de Tecnologia da Informação em autarquia, e dá outras providências. Disponível em http://www.planalto.gov.br/ ccivil_03/MPV/2200-2.htm. Acesso em 20 de abril de 2005.

. CASA CIVIL DA PRESIDÊNCIA DA REPÚBLICA .Diretrizes da política industrial, tecnológica e de comércio exterior. Brasília: Casa Civil da Presidência da República, 2003.

CAPRA, F. 0 ponto de mutação. São Paulo: Cultrix, 1982.

DESCARTES, R. Discurso do Método. In, Os Pensadores. Nova Cultural: Rio de Janeiro, 1996.

FAYOL, H. Administração industrial e geral. São Paulo:Atlas, 1994.

FERREIRA, A.B. de H. Dicionário Aurélio básico da língua portuguesa. 1. ed. Rio de Janeiro: Nova Fronteira, 1988.

FONSECA, M. de J. Sobre o conceito de ciência. Millenium - Revista do Instituto Superior Politécnico de Viseu, n. 30. Portugal, março de 1997.

HOBBES, T. Leviatã. São Paulo: Ícone editora, 2000.

INSTITUTO BATTELLE. Prospecção tecnológica: melhores negócios do futuro, desafios e oportunidades. Revista Parcerias Estratégicas, n.11, jun.2001.

LACOMBE F.J.M. e HEILBORN, G.L.J. Administração princípios e tendências. São Paulo: Saraiva, 2003.

LONGO, W.P.e. Ciência e tecnologia: evolução, inter-relação e perspectivas. Anais do 90 Encontro Nacional de Engenharia de Produção, v. 1, 42, 1989.

MAXIMILIANO, A.C.A. Introdução à administração. São Paulo: Atlas, 2000.

MONTANA, P.J.; CHARNOV, B.H. Administração. São Paulo: Saraiva, 2003.

MOTTA, P.R., Gestão contemporânea: a ciência e a arte de ser dirigente. 8. ed. Rio de Janeiro: Record, 1997.

MORGAN, Gareth. Imagens da organização. Rio de Janeiro; Atlas, 1996. 
RAMOS, A. Guerreiro. A nova ciência das organizações. Rio de Janeiro: Rocco, 1988.

RUIZ, J. A. Metodologia Científica - Guia para Eficiência nos Estudos. São Paulo: Atlas, 1979.

SAGAN, C. 0 mundo assombrado pelos demônios: a ciência vista como uma vela no escuro. São Paulo: Companhia das Letras, 1996.

TAYLOR, F.W. Princípios de administração científica. São Paulo:Atlas, 1970. 